\title{
Net-Working for a Living: Irish Software Developers in the Global Workplace
}

\section{Seán Ó Riain}

In 1992, I took the path followed by many young Irish people at that time and emigrated to the United States. In my case I left Dublin for Berkeley, California to get a Ph.D. in sociology. Within a year or two I found myself beginning to study the Irish software industry from 6,000 miles away in Silicon Valley. Through interviews with managers in Silicon Valley companies with operations in Ireland I investigated the dynamics of foreign investment in the Irish software industry. Email correspondence with managers of Irish companies in Dublin directed me to their Silicon Valley offices where I learned the basic history of the emergence of an Irish-owned software industry which was now itself becoming increasingly globalized. These contacts and other Irish people I knew in California put me in touch with Irish software developers working in the Silicon Valley area.

In the mid-1990s many of the young emigrants of the late 1980s and early 1990s were returning home, encouraged by the booming 'Celtic Tiger' economy. In early 1997 I followed these global connections and returned to Ireland to carry out more detailed research. It was time to live for a while inside one of the global workplaces which constituted the industry I was studying. I spent 12 weeks as a technical writer and sometime tester on a software development team in USTech, a US transnational corporation well established in Ireland. During this time I participated fully in the work of the team and wrote a User Guide for our product which was installed on the system as on-line help for users of the system. I sat in the same cubicle as the rest of the team, attended team meetings and interacted closely with them on a regular basis on decisions regarding the User Guide. After an initial period of suspicion of my motives, which may return once they read this chapter, the team members were very welcoming and helpful to me. Indeed the regular flow of contract personnel in and out of the team meant that I became a relatively well established team member.

By the time I came to work at USTech in Ireland I had made many of the connections and followed many of the transnational career paths which were such a big part of my co-workers experience. The five long-term members of the team were employees of USTech but were working on a contract designing a product for Womble Software, a spin-off from USTech headquarters in the US. My own life in the social sciences had mirrored the experiences of my friends on the Womble team - educated on different sides of the same college campuses, working at home and abroad on emerging meanings and logics, one foot in local culture, the other in the global economy. Software had seemed like a distant world only for ethnography to reveal the many aspects already familiar to me from life in the Irish knowledge worker diaspora.

During the time I spent with the Womble team, I uncovered a characteristic set of structures and dynamics of this global workplace. Although we sat at the centre of 
a wide array of local and global connections and of multiple career trajectories, the cubicle space we shared came to dominate our lives. The experience of local space was intensified for us, even as we sat in a global workplace. Time too was intensified as the project deadline became the defining element of our work, and to some extent, social lives. Out of this intensification of time and space emerged cooperation, innovation and career success but also burnout, individualism, inequality and pressures on family. It is these dilemmas and tradeoffs which constitute the 'contested terrain' of the global informational workplace. 
It is 4.15 in the afternoon. On the wall of the software test group in the Irish offices of USTech, a prominent Silicon Valley computer company, there are four clocks. At the moment they show that it is 8.15 a.m. in Silicon Valley, California, 10.15 in Austin and Fort Worth, Texas and 11.15 Montreal, Canada. Silicon Valley has just 'opened for business' and the software developers and managers in Ireland begin a hectic few hours of discussion with their American counterparts. The row of clocks evokes a smoothly working global economy, held back only by time zones, and a software operation which seamlessly manages a variety of transnational connections.

I hurry downstairs as I have a conference call to the US at 4.30pm Irish time (8.30am their time in Silicon Valley). 30 minutes later I am sitting in an open plan cubicle, along with five members of a software development team. Employed by USTech, they are developing a software product for a Silicon Valley start-up company called Womble Software. I have been writing a user guide for the product and am deep in discussion with Jane, the technical writing editor in Silicon Valley, and Ramesh, an immigrant to the US from India and the 'chief architect' of the programme who is in St. Louis in the heart of middle America. As my manager comes into the team area I put the conference call on the speaker phone. Now the whole 'Womble team' can hear the conversation.

As the conversation unfolds so does the mime drama around me as the team reacts to the flow of global communication into this cubicled 'local' space. When Ramesh suggests adding new features (creating more work for the developers around me) there is an explosion of displeased sign language including a variety of abusive gestures directed at the speaker phone. Since Ramesh can hear everything on our end this pantomime is conducted in complete silence. I have a hard time not bursting out laughing..... When Jane points out to Ramesh that it is difficult to write a user guide when the final screen designs for the software programme have not been decided upon (a common complaint within the development team two weeks before the product is released) there is an explosion of mimed cheering and barely controlled laughter around me.

This is just another day in the global informational workplace, a workplace which is home to increasing numbers of employees around the world. The dominant image of these workplaces is that of places lifted out of time and space, places where communication and innovation are free from the drag of local cultures and practices and untainted by power relations. Robert Reich argues that new information and communication technologies make it possible and even necessary to reorganize firms into 'global webs' and employees into global telecommuters ${ }^{1}$. For Reich these webs operate smoothly, destroying constraints of space and social structure, moving in conjunction with the ever-circling hands of the clocks on the USTech wall. The global 
workplace is 'lifted out' of its temporal and spatial contexts and becomes a 'pure' space for communication based on shared rules of interaction and understanding ${ }^{2}$.

Others argue that this perspective is too benign. The speeding up of the global economy destroys local space - the fact that Ramesh and the Womble team can participate in the same conversation at the same time means that they essentially share the same social and economic space, despite the physical distance between them. Time annihilates space, melting away 'solid' local places into the 'air' of the global economy ${ }^{3}$. This is not a neutral process however as the once autonomous local space of the worker is increasingly dominated by global corporations and the ever more rapid pace of economic life under capitalism ${ }^{4}$. Ramesh's presence a phone call, email message or plane trip away undermines the autonomy provided these workers by their local space.

The Womble team is certainly connected to other global workplaces - including Silicon Valley and St. Louis on this particular afternoon. They also experience the pressure of the global economy through the demands of Ramesh for new features. However, local space is not destroyed by these global connections. The Womble cubicle takes on a culture of its own, manifested in the mimed hostility to Ramesh's suggestions but also in the information-sharing, problem-solving and solidarity building within the team on an everyday basis. In fact, the demands of the global economy for increased flexibility and specialized learning actually make the local context and interactions of the global workplace even more critical. Efficient production and constant innovation require the construction of shared physical spaces where workers can interact and communicate on a face-to-face basis and where shared goals and meanings can be created and maintained ${ }^{5}$.

Global connections bring the pressures of the world economy into the heart of workplaces such as the Womble team cubicle. However, these pressures actually make local space and social context all the more important. The speed up of time and the extension of social space across physical distance in the global economy does not destroy space but in fact intensifies the impact of space in constituting successful global workplaces.

However, this does not herald a return to an era of workplaces dominated by localized social relations. This is because the importance of local social relations to innovation creates a dilemma for the global corporations who rely on this innovation. The local character of their work teams is essential to their efficiency but also poses a problem of regulating such localized relations from a distance. Ramesh may be aware that his proposals are not meeting with happy grins on 
the other end of the phone but he is also unable to directly regulate the team's behaviour because of his distance from the team and his only partial incorporation into the social space of the team. The typical managerial answer to this dilemma of control in the global workplace is to attempt to control the instrument of speed up and pressure within the global economy - time itself. The politics of the contemporary workplace is increasingly the politics of time ${ }^{6}$.

The most important instrument used to control time in the global workplace is the project deadline. Although Ramesh cannot control the everyday behaviour of the Womble team the parameters within which the team can operate are set by the demands of the deadline - the team members have a great deal of autonomy in how they work but the supervisor looking over their shoulder is time itself, with every decision measured against its impact on meeting the deadline. Ramesh's requests for new features are not considered on their technical merits but on the basis of their impact on the team's ability to meet the deadline. Even as the importance of space is intensified in the global workplace so too is time, in its manifestation as the dominant mode of control in these workplaces. Global workplaces are subject to a process of time-space intensification.

This chapter explores in detail the characteristic structures and dynamics of the global workplace under conditions of time-space intensification. The first part of the analysis shows the dilemmas posed for innovation in the global workplace due to the pressures placed on it by the intersection of the high mobility careers of software developers and highly mobile software firms. It documents how intense cooperation in localized workplaces makes it possible for such highly mobile workers and firms to forge an alliance in the pursuit of innovation and profit. A tension persists within this structure however - a tension between place-bound cooperation based on group solidarity and individual careers based on high rates of mobility between firms and places. This tension is reconciled through the dynamics of the workplace, which is analyzed in the second part of the chapter. The period prior to the project deadline is one of team solidarity and cohesion while the post-deadline phase is characterized by the fragmentation of the team as they use their social networks to position themselves for the next move in their career. The globalization of the information technology (IT) industry is seen to result not in a virtual economy but in a global industry organized around and through certain key places and regions. Within these global workplaces relations among workers constantly cycle through phases of cohesion and fragmentation as worker solidarity is mobilized for purposes of innovation but disarmed by the structure of careers in the labour market. The globalization of knowledge workplaces becomes an object of tension and conflict in the workplace, not simply an ever expanding process of increasingly pure communication and innovation nor an inexorable 
advance of the dominance of capital. Power relations in these workplaces are forged out of the interplay of mobility and place and of time and space which is examined through the rest of this chapter.

This chapter argues therefore that as the workplace stretches out across national borders local spaces such as the Womble team cubicle become all the more crucial to the operation of the global economy. Overcoming the constraints of international time differences allows organization across time and space but poses new problems of control from a distance - problems which are solved by the intensification of time through work team deadlines. Global informational workplaces are characterized not by the disappearance of time and space as realities of work life but by their increasing importance and intensification.

\section{Dilemmas of the Global Workplace}

Neither do these workplaces emerge tabula rasa onto the global stage, as a response to the prompting of the global market. In fact, the Womble team is the outcome of state development strategies, changing corporate structures and strategies and the emergence of new industries organized around knowledge creation. Indeed, the routine phone and email arguments between Ramesh and the Womble team would bring a glow to the heart of many industrial development agency officials in Ireland. The formation of connections to the global economy through attracting foreign high technology investment has been the cornerstone of Ireland's industrial policy since the late 1950s. The connection to the US has been particularly crucial - over 400 US companies have located in Ireland and some three quarters of jobs in electronics and software in Ireland are in foreign owned companies. Through the 1970s and 1980s transnational electronics and computer hardware firms located primarily low-level functions in Ireland and developed few links to the local economy'. Many of the transnational corporations used Ireland as an 'export processing zone' within the European market, taking advantage of low tax and wage rates and Ireland's position within European Union tariff barriers. Irish plants were at best weakly integrated into the core activities of the corporate parents as the typical Irish operation's activities were routine and relations with the parent hierarchical.

However the past five to ten years have seen a shift in the nature of the activities and the character of some of the foreign investment in Ireland ${ }^{8}$. Encouraged by the state industrial development agencies, many hardware operations began to grow software development centres as the information technology industry moved towards a focus on software and software became the strategic technology for these corporations. Local managers, usually Irish-born, were able to 
carve out strategic positions for their operations within the parent companies although their position always remained precarious. In cases such as USTech, local managers often developed relationships with customers well before discussing these new lines of business with their colleagues at headquarters. In recent years, subcontracting and business partnership relationships between US and Irish firms have expanded and the two economies have become increasingly closely integrated. Indeed, the apparent shortage of computer skills in Silicon Valley was one of the reasons why the Womble software contract went to the USTech Ireland office. Companies such as USTech Ireland were still limited by their place in the international corporate structure and often still concentrated on testing, support and consulting software work rather than on the strategic software development tasks. However, many were able to develop small to medium sized software development teams, closely integrated with the parent's operations.

USTech is well established in Ireland, having located there over fifteen years ago and becoming one of the early success stories of Irish industrial policy. For many years it was one of Ireland's primary computer hardware production operations, with a reputation for high quality. The hardware manufacturing operations of USTech Ireland were dismantled with massive layoffs in the early 1990s, leaving local management scrambling for the operation's survival and turning to a complete reliance on the local pool of software skills. Their links to the global economy have diversified with a proliferation of customers, partners and internal corporate sponsors replacing their previous model of reporting directly to a single office in the US. The software development contract for Womble reflects this change as there was little opportunity within the previous corporate structure for such arrangements.

Womble Software itself is a perfect example of the 'global web' corporate structure which Reich argues is becoming the norm. Formed as a spin-off from a large hierarchical corporation the company is part owned by the four founders, part by USTech itself, part by a major customer and the rest by a venture capital fund in Silicon Valley. It has no more than 15 employees of its own. The development team is based in Ireland and is officially contracted to provide software development services to Womble. The screens for the programme are conceptualized by Ramesh but all the development work necessary to turn them into computer graphics is done in a small graphic design house just outside San Francisco. The helpdesk staff which users reach if they call with a problem is staffed by the trained employees of a helpdesk contracting company. The technical writers who write the on-screen help for users are all hired on a contract basis. In place of more rigid, hierarchical organizational structures we have a shifting web of connections forged into a relatively fleeting alliance. 
Mobility and Connections in the Global Labour Market

Womble is not only, however, the prototype of the 'global web' organization but also conforms to a new model of computer industry careers. In this model, the dominant metaphor of IBM's promise of lifetime employment ${ }^{9}$ has been replaced by the image of the freewheeling Silicon Valley engineers who expect little from their employers and will jump ship for more money or more challenging work at the drop of a hat. Both of course are stereotypes, but there is more than a grain of truth in the emergence of cross-firm careers as the dominant pattern in software companies in Silicon Valley and in Ireland ${ }^{10}$. These trends are intensified by a shortage of experienced personnel in most countries' software industries ${ }^{11}$. Certain skills are in particularly high demand - including the Unix, $\mathrm{C}++$, database and Java skills of the employees in the Womble team. The variety of local and global connections of the team reinforces the tendency towards mobility by providing the channels of information about new opportunities and the social contacts for facilitating moves to those emerging areas. Negotiating the commitment of highly mobile employees becomes the critical dilemma facing software firms, a dilemma which is addresses in the following sections of this chapter.

In industries such as software the typical career pattern now involves a number of moves between organizations during a career and there has been a clear shift from internal labour markets to job-hopping between firms. Where employees stay with the same firm their tasks and level of responsibility changes on a regular basis. Furthermore, professional migration into both the US and Ireland has been increasing, with transnational intra-firm and inter-firm careers expanding. As can be seen from the career histories described above, the high mobility career pattern with little attachment to the employer (or to the employee for the firm) has become a reality for these particular software developers. Even in the still 'semi-peripheral' region of Ireland, the careers of such software developers have converged quite significantly with those of their counterparts in the leading high-technology regions such as Silicon Valley or global cities such as New York and London. A survey of 250 software firms in Ireland in 1997 revealed that a quarter of the firms had employee turnover of $25 \%$ or more in the previous year ${ }^{12}$.

These trends were evident in the experience of the Womble software team members. The team consisted of six people (including myself) during the time I was there. Séamus, the team leader, has been at USTech for 7 years. In that time he has held four completely different positions working as a computer test engineer, software systems test engineer, information systems support and software development team leader. The rest of the team has been assembled over the 
past 6 to 18 months. Conor, 6 months out of college, still receives job postings from his college career counseling service every two weeks. If he follows the industry pattern he will most likely leave USTech in 18 months time or so when another software company will be glad to pay him well for his skills and experience.

Jim and Paul are employed on a contract basis. Dan had also been a contractor and took a pay cut of almost 50\% when he accepted a permanent post in order to get a mortgage from the bank. Paul's history is one of a 'software cowboy', using a series of lucrative short-term contracts to see the world without being tied down by business, social or personal obligation. Jim and Dan have pursued a different path - they have at times been employees, contractors, entrepreneurs or a number of these statuses at the same time. The line between employer, self-employed and employee begins to blur in such careers.

Transnational experience is a major part of the developers' careers. Dan is originally from Hong Kong and came to Ireland to study, subsequently pursuing a career in software. Almost all the contractors who work with the team while I am there have emigrated at one point or spent a significant amount of time working on contracts abroad. Indeed it is the contractors who are most openly dependent on mobility for their career advancement. They are usually brought in for their quite specialized skills and are often given tasks working on relatively self-contained parts of the system being designed. Their need to communicate with other team members may be minimized although this remains a critical part of their effectiveness. Sometimes, contractors stay with a team for a relatively long time. Jim, a contractor, had been with the team for longer than the two permanent staff and had successfully resisted efforts to make him take a permanent position. Indeed, he was the de facto deputy team leader. Mobility across organizational, employer/ employee and national boundaries has therefore been central to these workers' careers and is understood by all to be the background to workplace interactions and relationships.

Mobility is also the team members' key bargaining chip with their employers. One lunchtime Conor, myself and Michael, the group manager, ended up sitting together for lunch. We had somehow got onto the topic of the difficulty of getting people for the jobs that were available within USTech. Conor went into great detail on the job offers he had received on leaving college and on the ever-improving job market for graduates, until Michael quietly finished his lunch and left. Conor turned to me and asked "what did you make of that? I wanted him to know there are plenty of other jobs out there. What I didn't say is that I've been getting job offers every 2 weeks through the college". 
Mobility then is the dominant career strategy within the software industry as a whole and within the Womble software team. There are also however constraints on the mobility system for both the firm and the employee. The firm will sometimes try to get contractors with crucial product knowledge to become permanent employees so that their knowledge is kept within the organization. In the Womble team Dan had gone permanent because he had to get a mortgage whereas Jim, already having a mortgage, was able to resist the efforts of the project managers to have him become a permanent employee. Neither are employees completely free to exercise their mobility. Companies are reluctant to pay employees if they threaten to leave, as they are likely to set a series of threats in train which may spiral out of control. However, companies will make exceptions on occasion as long as they can keep them relatively secret. In general, the threat of mobility serves as a background possibility which keeps the company's mind focussed on getting training for key employees, increasing their pay and so on in order to put off the possibility of leaving before it arises.

Employees must also be careful not to get a reputation for being unlikely to stay at a company. "If you look at a CV and see that someone has moved every 9 months or so you have to wonder if they'll stay here any longer than that. But if they stay 2 or 3 years then you know they will contribute something” (Séamus). The degree of demand for a developer's particular skills is the critical factor which affects their bargaining power through mobility. "When I was in Belfast, you would be on contract if you couldn't get a permanent job. Here, you would be permanent if you couldn't go on contract. It's just a question of how many jobs there are” (Paul). This can even override the threat of lost reputation if the demand is high enough - "they mightn't think you'll stay but if they need you badly enough they'll hire you anyway!” (Paul). Industry norms have developed around the 'proper' way in which this mobility is to occur - mobility between jobs is not unlimited but is a strategy which must be carefully managed.

Mobility therefore becomes a taken for granted element of the composition of software teams such as the Womble team. Relations with co-workers develop in the context of a constant awareness that the members of the team might be dispersed at short notice. This can happen either by corporate decision (the team beside us was disbanded overnight when USTech in Silicon Valley halted development of the product on which they were working) or through the decision of individuals to leave the team. Mobility then is a double-edged sword - the advantage to employees of being able to leave with few repercussions is balanced against the lack of constraints on companies changing employees' responsibilities and even getting rid of them (within the bounds of the law). Indeed, the Womble team was itself eventually disbanded when development work was moved back to the U.S. and ultimately when Womble itself went out of 
business. These advantages and dangers are all the more significant for contractors. Nonetheless these highly mobile careers seem to pose a clear threat to the ability of software developers to work together in a cohesive way while working on a common project. The intensification of space in the global workplace provides some of the critical elements of the answer to this organizational dilemma.

\section{Putting Work in its Place}

While software developers may move quite regularly from job to job they have an intense relationship with each other once in a particular job. In informational and design work the labour process is usually organized in the form of teams working closely together on specific projects. Some see these as virtual teams interacting purely through cybertechnologies - the process of generating cooperation among employees is assumed to be unproblematic ${ }^{13}$. Indeed, Ramesh himself subscribed to the theory of the virtual economy in a 'Thank You' E-mail message he sent to the contract graphic design firm in California:

"Our project team was truly an international virtual-team, with up to 8 hours of time-zone difference among the different team members. We expected you to work at such a hectic pace, yet, we also demanded extreme flexibility from you in all respects. It is very rare that anybody of your caliber would be able to excel on both these fronts."

However such teams are usually located in close proximity to one another as this allows the team to handle the complex interdependencies between team members through easy and constant communication and allows them to build a coherent collective identity which becomes the basis of cooperation within the team.

The sheer volumes of information and the dependence of each member of the team on the design decisions of the others makes the easy interaction of the team members critical. As Jim at USTech worked on the user interface screens he would intermittently call over to Paul two desks away 'what did you call the course number variable, Paul, I can't find it', 'are you working on the database at the moment, it's a bit slow', 'who’s doing the security screens'. The questions and answers are discussed on the way to and back from breakfast and lunch, although by common consent rarely during the break itself.

By contrast, information flows to the US can be patchy and tend to be limited to broad strategic decisions. A developer in Silicon Valley would have great difficulty in developing this product along with the team around me. Indeed my own easy ability to ask the developers around me for 
information fifteen times a day contrasts with the difficulties I have sharing information with Jane in Silicon Valley, leaving me idle for mornings or afternoons as I wait to be able to call her in the US to clear up some minor misunderstandings. Where such transnational 'virtual' relationships work they are constantly supplemented by travel to meet the team(s) in the other country - Ramesh was a regular visitor to the USTech Ireland office. This clearly also affected how much employees could learn from their colleagues. The experience of working with the more experienced and skilled developers taught others the skills and tricks which turn a computer science graduate into an effective and innovative programmer ${ }^{14}$.

The accountability of team members to one another is also much more easily sustained in faceto-face interactions than in 'virtual' communications. This can happen even in the most apparently 'flat' and non-hierarchical of organizations. I was caught in a bind during the conference call when Ramesh asked me, an untrained technical writer with a long and largely irrelevant training in sociology, 'Seán, are you happy with the proposal to put the toolbar in the help box?'. While I was being formally asked to participate in a design decision, the social structure of this global organization made me think first not of the implications of my decision for the system itself but of my loyalties to the fuming developers around me. Even the periodical visits of Ramesh to Ireland do not solve the problems of miscommunication and alienation felt by the Irish team. As Michael, the business manager of the group, said "having a remote manager has made getting a process of communication in place a lot more difficult”. Problems which would require solution in a face-to-face context can be swept under the carpet or become a figure of fun in a context where communication is by phone and the Internet.

The issues which can be resolved in a daily phone call to the US are those relating to the strategic technical decisions, which were hotly debated with Ramesh every day by Séamus, the team leader, and even the other members of the team. E-mail is generally used within the team to pass on relatively routine information to one another - whether that be between the team members or between Seamus, the team leader, and Ramesh. On one occasion, although we sat less than ten feet apart, Conor and myself exchanged a series of emails about problems I had found with the programme and the fixes he had made - without ever turning around to speak to one another. Only when it became clear that one of the problems was more complex than it appeared did we discuss the issue 'face-to-face'. Email also appeared to be a valuable tool for the team members to stay in touch with their friends throughout the industry. I was able to combine my membership in the 'global ethnography group' with participation in the Womble team, largely unbeknownst to anyone else on the team. Other team members seemed to use email similarly - every now and then someone would read out a joke they had been sent by a friend or 
tell us about the bonuses being offered at other companies for recruiting a new employee. Overall, while face-to-face interactions were critical to conveying complex information or to building and sustaining trust, computer supported communication seemed "especially suited to maintaining intermediate-strength ties between people who cannot see each other frequently” ${ }^{15}$.

USTech is also located within one of the locations best known for information technology within Ireland. Located in a city which is attractive to the young people which dominate the software industry, USTech also benefits from access to a large pool of local skilled labour and from the connections of the Womble team members to the broader 'culture of innovation' within the region. The Womble team members, especially those who have had more mobile career patterns, have many connections to people through the local industry and will often recount stories of people they know in common, people who could be hired by the team, other developers they met around the city and discussed their work with, and so on. Their high mobility careers are also sustained through social ties to others in the industry who can provide the team members with information on job opportunities and can provide formal or informal recommendations to employers regarding the team members' competence. It turns out that both the high mobility careers and the face-to-face interactions which mitigate their corrosive effect on workplace cohesion are supported by the emergence of this regional 'innovative milieu' ${ }^{16}$.

Face-to-face interaction, localized social relations and electronic networks each structure the global workplace in important but different ways. Clearly face-to-face interaction does not guarantee good communication or cooperative working relationships. However it makes it a lot easier than trying to achieve these across 8 time zones and numerous digital interactions. Ease of communication and mutual accountability at 'work' ensure that spaces defined by face-to-face interaction remain a critical component of the global workplace, even as virtual spaces proliferate.

\section{A Globalized Local Culture}

These globalized places also take on a distinct culture which reinforces the cooperation and cohesion produced by the organization of work itself. In many ways even these human paradigms of the global economy are 'global locals', bringing distinct 'local' cultures to the global stage and remaking both global and local social relations in the process. This small open plan team area may be a globalized space but it is one which has a clearly defined local identity and which interacts with the global economy with caution and at times with difficulty. Some have argued that such tensions between the local and the global are born out of a traditionalist 
resistance by the local to the cosmopolitanism of the global ${ }^{17}$. However, the Womble team do not resist the global in and of itself but contest how the global should operate, showing disdain for the mismanagement of the global by the remote managers.

This can be seen most clearly in their perceptions of American software developers and managers. As an Irish manager at USTech told me "the test group here was the best in the corporation and they were really saving USTech with their customers in the field. So we had all these American managers coming over telling them they were the greatest and how they were the best thing since sliced pan. That's OK the first time but after a while the people here started saying among themselves 'quit the bullshit - if you think we're so great give us a raise or at least buy us a few pints'”.

This disjuncture was shown up dramatically after one particular bout of giving out about the US managers of the team. Séamus, the team leader, summed up the relationship to the US parent ironically:

Séamus: It's not as if there's 'us and them' or anything.... It's not even that, it's just 'them' really!

Jim (wearily): Yep, they're the enemy!

Nonetheless, the Irish managers and developers tend to work very successfully with their American counterparts, accepting some aspects of US corporate culture while maintaining a clear rejection of many aspects of the Americanized environment in which they find themselves.

The developers themselves comment on their own homogenous team culture, despite the fact that Dan is from Hong Kong:

Jim: What would we do if a black guy joined the group, who would we pick on? Conor: Or a woman?

Jim: Séamus, you can’t ever hire a black woman!

Seán: There’s always Americans to pick on....

Séamus: Yeah, but they’re too easy, there’s no challenge in that (laughter)

The mention of a 'black guy' is largely rhetorical as I never heard any comment within the team directed against 'black guys'. The team culture was clearly masculine and there is no doubt that this culture could be self-perpetuating ${ }^{18}$. 'American' is also somewhat ambiguous as Ramesh, the 'American' with whom the Womble team members have the most interaction, is originally from India. On a different occasion, three members of a different team discuss their Indian boss in the US with Conor and myself: 
Pat: We have one too - Ranjit

Conor: Ranjit that, sounds like something out of Aladdin

Peter: (Says something imitating Ramesh's accent). That's racist that is (i.e. criticizing himself, very serious about it).

Bob: Yeah, that's an 'ism', that is. That's racism.

Pat: They're (Indian software developers) probably over there saying 'those bloody Micks'

Aidan: Yeah, saying ' drinking pints of Guinness over their computers’

'Difference' on a global scale is an everyday part of these software developers' milieu although it is negotiated within a strong homogenous local culture. This was also evident in the team's relationship to Dan (from Hong Kong). In fact while the culture of the team was strongly male and Irish, members of the team was highly aware of this culture and most would criticize racism and sexism which they saw elsewhere. On one occasion two other team members and myself were both shocked and amused on hearing Dan, who had been born in Hong Kong, slander a visiting technical trainer who was himself Pakistani. 'The other' was accepted as an everyday part of life for Irish software developers and helped to define the team identity. When Dan revealed his own criticisms of another Asian ethnic group this disrupted the assumption of a single 'other' and was both surprising and funny to us as team members. It also revealed the unspoken assumption within the team that Dan's behaviour and attitudes regarding race were subject to different rules than those of the Irish born team members.

While the team members worked relatively easily with people of a variety of national, ethnic and racial backgrounds they consciously maintained a strong local team culture. Operating in the global workplace requires them to work with and around 'difference' but by the same token the less hierarchical forms of economic domination also allow them to maintain their local culture within these global connections. There is also a strong pragmatic element to this ability of people from different backgrounds to work together in the global workplace. One of the Womble Software managers took us out for a meal when she was visiting from the US. Half-way through the evening I commented to Pat, a contractor, "she seems OK, decent enough" to which Pat replied “well, when you come to discover the jungle you have to play with the natives".

Not only then are the Womble developers 'global locals' but they also think of themselves as such. Their highly mobile careers and relatively fleeting association with one another in the workplace demands an intense experience of a shared space and culture in order for them to create a cohesive work team. The team members use elements of a shared culture from outside the team to create this solidarity but are also able to incorporate aspects such as Dan's non-Irish 
racial and ethnic background into the team through the over-riding emphasis on work and technical competence. While these local team cultures are quite likely to be exclusionary of women and other ethnic groups as indicated in the quotes above, they are also flexible enough to accommodate the presence of such groups within the dominant team culture when necessary. Place, mobility and the global workplace are not necessarily in tension with one another as they might appear on first glance but are in fact symbiotic, underpinning one another's importance and sustainability.

In short then, globalization does not mean the end of place. Instead it creates places which are increasingly 'between' other places and have ever deepening connections to other places. The high mobility career pattern typical of the software industry poses a threat to the work team cooperation, commitment and cohesion necessary for innovation. The intensification of space through the dense social networks of the team and the region provides a solution of sorts to this dilemma. However, local networks also serve to reproduce mobility as developers use their connections to engineer their next move. Mobility and place sustain one another but also remain in tension within the structure of the global workplace. In order to understand how this tension is resolved we need to go beyond the intensification of space in the structure of the global workplace to an analysis of the dynamics of that workplace, set in train by the control, regulation and intensification of time.

\section{The Dynamics of the Global Workplace}

The mechanism for controlling the software development team is the project deadline. As it is impossible for the final design specifications to provide solutions to every issue faced by the team and the actual work done by the team is difficult for management to supervise directly, the deadline becomes the focus of management and team efforts. "Do what needs to be done to get this specification working by the deadline" is the broad task of the team. The deadline is the mechanism by which management brings the intensification of time into the heart of the team. It is also an attractive mechanism of control since direct authority over the work process is undermined by the expertise of the employees and the need for rapid communication and cooperation. In contrast time can be regulated through the use of the deadline with only a limited local managerial presence and with relatively little ongoing exercise of managerial authority. This deadline then becomes the stimulus which sets the dynamics of time-space intensification in motion in the global workplace - leading to a pre-deadline phase of team introversion and a postdeadline phase of extroversion. 
The Womble team schedule had three main phases - a middle period of 'normal work', a hectic period before releasing the product at the deadline and a beginning period of rest and negotiation after the deadline and the release have passed. The character of the team and the issues it faces change as the team members go through these stages of the cycle together. I join the team, as I did in my fieldwork, in the hectic pre-release phase and leave them as the post-release phase winds down.

Introversion before the Deadline: A Team Against the World

In the weeks before March 1st., the release date for our product, life in the Womble cubicle becomes busier and busier. The team works longer hours and becomes more and more isolated from the life of the company around them. Internally, the team becomes more cohesive, communication becomes more urgent, technical arguments take on a new edge and any delay or new instruction from outside the team is met with a barrage of criticism. The graphics for the screens of the system (i.e. what the user sees when using the system) are delayed in coming in from the graphic design house outside San Francisco. The Womble developers grow more and more impatient, furiously criticizing management and the graphic designers for their incompetence. The time allotted for particular development tasks is counted in weeks and then in days. From time to time, a particular problem is put aside for the March 10th. release which will contain the fixes for the initial bugs (errors) in the system, creating some dissatisfaction among the developers:

Conor: We're all tired, we've been at it for two months really. It's a lot of pressure. Something every day. There's no time to take a day and research something. We need a week to go over some of the bigger issues, have some meetings, go over things, you know. There's some dodgy code in there too.

While not as long as the hours worked by some other software development firms in Ireland the work hours do start to creep up toward 60 a week. Séamus, the team leader, works constantly, often late into the evening and the night.

Weeks earlier, Conor had told me:

I've a feeling this is the calm before the storm. My attitude when its calm is get out of here at 4 or 5 cos when it gets busy ......... You have to draw the line yourself as far as hours go, you have to say once in a while "sorry I have something on tonight, I can't stay". You have to keep your standard hours around 39/40. If you let your standard hours go up to 45 then they'll still come to you and ask you to do a few extra hours that evening, they won't think about that extra 6 hours you're doing as part of your standard. It's up to yourself to draw the line. 
As the deadline nears however, he ends up staying late and coming in two weekends in a row. While not impressed at having to work these long hours, they are largely accepted as the industry norm. In the Irish economy as a whole managerial and professional workers, especially in small firms, tend to work the longest hours and work a great deal of unrenumerated overtime: "Ireland may be a long way from the Japanese or North American patterns of executive working time, which involves managers working particularly long hours .... as a normal feature of managerial careers, but the trajectory of change is in this direction”. The authors of this study argue that the same findings apply to professional workers, although the trend is somewhat weaker ${ }^{19}$. Among the team members, proposed legislation limiting working hours is discussed ironically: Séamus: I wonder does Ramesh know about the European Social Charter limiting the working week? 43 hours per week or something.

Conor: Great!

Jim: It's 48

Conor: $\mathrm{F} \# *$ !, that long

Jim: Yeah, 48 for each company, 48 for Womble and 48 for USTech!

Such hours and constant pressure take their toll - the week after the release I bumped into Paul on our way in to work:

Paul: I was feeling crap lately cos I've been under a lot of pressure and everything. But now I feel great after having that day off.

The impact on the developers' personal lives is also clear from a conversation weeks later before Ramesh arrives in Ireland to take us to a promised celebration dinner.

Jim: Maybe we'll all meet up. I hope he doesn't meet my wife. She has it in for him.

Séamus: Herself and Linda should get together so. They have a lot in common actually - they're both vegetarians too.

Sean: Except when it comes to Ramesh! (Laughter)

Jim: I see you've met my wife!

However what appears to be deep antagonism to Ramesh during the pre-release stage fades away in the post-release phase. While the developers' complaints about management making their life more difficult persist their intensity wanes so that when Ramesh comes on a visit to Ireland after the release he is quite warmly welcomed (he is also quite well-liked by the team members on a personal basis). Apparently however, the complaints do not fade as quickly for the developers' families who experience only the long hours and intense demands on their personal life without sharing in the collective team 'buzz' of getting the product out in time and working well together.

As well as attempting (with little success) to limit their hours, the developers try to protect themselves against the follies of management in other ways. The team responds to the pressures 
from Ramesh and the outside world by turning in on themselves, by becoming increasingly introverted. Having a manager on the other side of the world allows the team, including the team leader, to screen information from Ramesh in order to let the team balance the technical and time demands to their own satisfaction. Having encountered a particularly thorny problem, the team finally found a solution:

Jim: So we're going to do that then. Ramesh never needs to know about it. So we can have it set up the way we want it and he'll have it the way he wants too.

Paul: So we're going to do it the sneaky bastard way

Séamus: I like the sneaky bastard way!

Paul: And Ramesh never needs to know

Séamus: No, no. Well done gentlemen!

Jim: Just don't say anything about this on Monday when Ramesh is here!

In many cases the reason for this screening of information was to avoid Ramesh's interference with a solution which the team considered to be the most technically effective. At other times, the goal was to avoid any extra tasks being given to the team before the deadline. On one occasion Ramesh sent an E-mail about a 'work around' the team would have to do around a problem in the database they were using. Not realizing that Dan had been working on this issue for a while now, he set aside a day the week before the release for Dan to work on it. Jim: Dan will have that done today. Sean: So what about the day Ramesh is setting aside for it next week? Jim: Oh God, I'm not going to tell him we already have a solution. He's already expecting it to slip a bit so if we get it in on time he'll be really happy. I think we're a little bit ahead of schedule but he thinks we're a bit behind so that suits us.

In general, team members were careful to protect themselves from undue interference from HQ in the US and left the negotiation of deadlines and larger technical issues to Séamus the team leader. As Conor advised me when I had sent an E-mail to Ramesh about a problem in the 'help' screens:

Conor: Be careful what you send to Ramesh. Cc it to Séamus or better yet send it to Séamus first, let him decide. That's what I do. You have to look after your own behind first you know. I try to get involved as little as possible with Silicon Valley, I give it to Séamus. That way I have a buffer between me and the US.

The team could also use the Product Technical Specification (PTS) as a rhetorical device with which they could if necessary justify not doing certain tasks. The technical specification for the product was a detailed document outlining the technical basis and logic of the system and supposedly defining the key aspects of the actual development process. However, in contrast to the expectations of formal models of software engineering, the specification document was 
necessarily vague in places and could not capture all the technical dilemmas which arose during the development process.

Dan, sitting beside me, constantly justified his resistance to certain new tasks which arrived in before the deadline with the refrain "if it's not in the specs, I'm not doing it". On one occasion Jim and Paul discussed a new requirement for the system which had come in from Ramesh in an email that morning:

Jim: Is it in the specs?

Paul: No

Jim: Well screw it then, we don't need to do it

However they later came up with a solution to the problem which they knew was not strictly compatible with the technical requirements of the PTS but which would solve the problem satisfactorily. In this case they were willing to drop their apparent dedication to following the specs in order to try to slip a different solution past Ramesh:

Paul: I have a feeling we're going to get $\mathrm{f} \#$ ! ed on this. I think the thing to do is to keep our mouths shut, do this what I'm doing now, present it to them without saying anything and then if they come back saying 'we're not supporting that' then OK. Cos if I just say it to him, he'll just say "Noooo ........"

Jim: Yeah, he does that

At times the dissatisfaction extended into banter about collective action among the employees. When new changes to the computer graphics for the screens arrived one week before the deadline the team was furious:

Conor: I'm going on strike

Sean: That'll make history, the first strike in the software industry

(Dan laughs ironically)

Conor: You know what last minute changes means, it means you work your arse off

Dan: If its something we've agreed already I'll work my ass off. But if its last minute changes I won't. It has to be reasonable, or else its 'see you later'

Later at breakfast Conor brought up the issue again:

Conor: I'm going on strike, I say 'in with the union'

Jim: Well if its minor changes to what we still have to do then we'll do it. But if its changing stuff we've done already then we're not doing it. 
The others on the team agreed. Conor's view was that the developers themselves were not an elite as it was the companies who were making the real money. Of course, software developers are generally relatively well paid:

Jim: Maybe we should join SIPTU (the largest national union) and get union rates. But who wants that kind of pay cut?

Conor was however the only team member who put the complaints of the team in the language of collective action. Despite the close ties between the team members and the generous cooperation and help they gave to one another, the solidarity of the team is cast almost entirely in negative terms. They need to protect themselves from the interference of management and less competent designers and developers in order to get a technically good job done under reasonable conditions. This is achieved largely by controlling the flow of information out of the team as best they can. Collective efforts to negotiate what such reasonable conditions might be are not on the agenda as industry norms around hours, unreasonable deadlines and so on are rarely challenged. However as the team comes together to resist the pressures of time intensification they create the team cohesion and work intensity which allows them to meet the challenges of innovation in the global economy. Ironically, it is the team's resistance to corporate interference which creates the conditions under which the team manages to meet corporate innovation goals.

\section{Extroversion after the Deadline: A Team in the World}

After the release the team goes into temporary collapse with the work pace slowing dramatically. As work starts to pick up again, I notice that the solidarity of the team in the pre-deadline, introverted phase has fractured somewhat. During the period after the release individual team members begin to negotiate their roles in the next phase of product development. The team begins to fragment as the focus of the team shifts from getting the work done to building a career and as the team members become extroverted looking outwards to their future opportunities within and beyond the team.

The next deadline is 3 to 4 months away and requires the implementation of the system in the Java programming language. Implementing it in Java should make it possible for the system to run on any computer and to use any database system where training content is stored. This move to Java is critical for the product, although difficult because since it is a new language Java development skills are in short supply and many products do not have Java 'drivers' which will enable them to work with a system designed in Java. From the team members' point of view this is a great opportunity - training in Java and experience in developing a complex product in the language will be a huge resource for them in the labour market. 
However, the distribution of opportunities for training and for valuable experience is not determined by the technical requirements of the product. It is an object of negotiation within the team, negotiation which takes place through the social networks among team members and between team members and the team leader and managers. The issue is rarely mentioned publicly, let alone discussed collectively. Furthermore, the move to Java is a gradual one and each stage produces different sets of conflicts.

The move to Java represents an opportunity for the Irish team but also a threat. As the team moves to a new technical phase in the development this opens a 'window of locational opportunity' for Womble Software. Despite the Irish team's advantages of knowledge and experience of the system, there is still a danger that development work could move back to the US. One team meeting discussing the move to Java produced the following exchange: Michael (Business Manager): We had to get a Java person in Ireland. Ramesh had someone in the US, but we couldn't let that happen, we couldn't let it go there.

Paul: Yeah, you don't want to let the development stuff leak back to the US. If it starts it'll all end up back there eventually.

The Irish team scrambles to gather together Java skills and to give Ramesh the impression that we have more skills than we do. Later it is my clear impression that Ramesh knows the level of skills in the Irish team but that he has developed a trust in the Irish team that they will be able to get up to speed on Java in time.

Of course, even keeping the Java work in Ireland does not solve the issue of how exactly the need for Java knowledge will be solved for the team. This issue arises first in relation to a totally different problem. The system can now run only on computers which have Unix or Windows NT operating system software. The system needs to be able to also run on computers with Apple's Macintosh operating system. One quick way to achieve this is to buy a software product from another company which can 'compile' the computer code so that it will work on Macintosh systems. However, this will add 2,000 pounds to the cost of each copy of WebLearn for Mac. Instead it is decided to adjust some parts of the system using Java which will achieve two goals: make the system work on Mac and begin the process of implementing the system in Java. The team must look for a contract developer to do this work before the release date. Michael: I think we'll have to get a contractor. Pat is up there with the porting team at the moment, he should be able to do it. Jim: Yeah, Pat is very good. 
Michael: Under normal circumstances we'd put that 2,000 into training somebody on the team so that they could do it but we don't have the time at the moment because of the release date coming up. So I think we should get Pat.

There are many ways therefore to incorporate new skills and sources of knowledge into the team. The strategy of buying a product made by another company which embodies that knowledge is rejected in this case due to its cost. Training current employees is always an option but is often overlooked in the hectic development schedule. No one can be let go to a week long course with the deadline hanging over the team. The team also missed out on other training opportunities while I was there due to this pressure of time. Finally, bringing in someone with the necessary knowledge is chosen as the strategy, less than satisfactory in the long-term but necessary given the time constraints.

The issue of hiring contractors versus training employees is of course a sensitive one: Conor: Be careful we don't keep getting contractors to do Java stuff and none of us get to go to the training on it.

Jim: Sure, I know. I'm thinking if we get someone on Java he'll have lots of ideas about things to do in Java and that'll create lots of work for us to do in Java.

This is a particular danger as while contractors may only come for a short while, they often stay longer as they develop a knowledge of a particular piece of the product or become valuable to the team in a particular area. Even I, as a novice technical writer, become valuable in that having developed a knowledge of the system I would be able to write the help for future editions more quickly than some professional 'tech writers' with no knowledge of the product.

This tension between contract and permanent employees becomes clear in the negotiation of team roles and opportunities for working with Java. It is in this internal competition for Java work that the fragmentation of team solidarity and the shift from an introverted to an extroverted orientation within the team is clearest. When Paul, a contractor, declares that he is starting to teach himself Java and wants to do a Java implementation of his part of the system, this meets with some (private) concern from some other members of the team: "I thought he was just here to do that section of the system and not to do this Java stuff”. Dan is particularly worried about the involvement of contractors in Java work to the exclusion of permanent employees:

Dan: The 3 contract people are doing Java and the 2 permanent people are doing everything else. It is not right. Conor and myself were told in our one-on-one reviews with Michael that the permanent people would get Java training, they would get priority over the contractors. Michael said that they didn't want to give it to the contractors first cos they could just leave and take it somewhere else. But that's not how it's going to be - over the next few months they will be 
doing Java and we will be doing everything else. I was talking to Conor about it yesterday. He is aware of it.

Sean: Will you say anything about it?

Dan: What can I say? My attitude is if something is wrong and I can't change it then I just leave and go somewhere else. It's as simple as that. It doesn't make sense from USTech's point of view. They are paying all this money for contractors and they are not paying for training for permanent staff. In the end they just pile up the costs for themselves. It's crazy from USTech's point of view. And from my point of view (laughs ironically).

Dan did eventually talk to Séamus, the team leader, about this and received assurances that he would be doing Java work. Paul's growing interest in other advanced technical areas also helped defuse the situation to some extent. However the negotiations continued as I left. Indeed on Ramesh's second visit he treated the whole team to a dinner and a night out on the town. Each one of us, as we sat over dinner and wound our way through the city streets, discussed our future roles with Ramesh - I myself talked over the possibility of doing some further technical writing on a contract basis once my fieldwork was over, Paul discussed his hopes to do some field consulting on the product, Jim and Paul their plans to work on a new technical area of the product, Conor his desire to do work with Java in a particular application of our system. Indeed we also put in a good word with Ramesh for each other where the different roles seemed complementary. In competition over certain areas, the team members helped each other out in others.

We can see therefore that the team solidarity of the pre-release phase becomes more fractured as opportunities for training and learning become a focus of conflict within the team. However, the conflict is submerged and operates through a complex set of social networks and shifting alliances among team members. These ties interact with the formal categories of permanent and contract employees to produce a politics of learning and skills within the team. These local dynamics are intimately connected to the nature of the opportunities in the global market for knowledge embodied (in this case) in the skills of US developers and the products (software tools) available to carry out certain tasks.

The pre-release phase revealed the nature of the local and global solidarities of the team, with local solidarities increasingly pitted against global interference as the local team fought for the space to achieve the 'global' goal of releasing a good product in the way that they saw fit. The post-release phase reveals more schisms within the team and shows how the local team is forged out of a range of alliances between local and global employees and managers. The mobility of team members through various learning paths within the team and outside of it is negotiated in this phase, laying the foundation for the next pre-release phase in three to four months time. 


\section{Time-Space Intensification as the Politics of Globalization}

The emergence of a global information economy has transformed the character of the workplace for many employees, including those within informational industries such as software. Many authors argue that the globalization of work destroys place and locality, creating a placeless virtual workplace. Against this view, this chapter has argued for a concept of globalization which emphasizes the organization of the global economy through particular places and regions and the critical importance of patterns of mobility of people, information and resources within and between these regions. These changes in the territorial organization of capitalism interact with an organizational restructuring characterized by the decentralization of work and firms. While some authors argue that these organizational changes will bring relative equality and a rough and ready economic democracy, this chapter has shown that new forms of power operate within these new organizational forms. Ethnography reveals that we cannot simply 'read off' concrete social practices and power relations from a particular organizational and territorial structure of work. Instead we find that a new ground is emerging upon which the struggles of the global informational economy will be waged - a new set of social identities, resources, interests and issues are created which will be the basis of the politics of the global workplace in the years to come.

This new 'contested terrain' of the global workplace is a system of time-space intensification where workers in the global workplace experience not the 'end of time and space' but their raising to a new level of intensity. Space is intensified by the necessity of local cooperation and the increased use of project teams in the face of the challenges posed by the global economy. Time becomes an ever more pressing reality in the deadline-driven workplace. This time-space intensification shapes the structure of both work and careers in the global workplace. Careers are built using mobility between firms to bargain for improved wages and access to technical learning and these mobile careers only increase the importance of close interactions and strong local cooperation while working on any particular project. Out of these underlying structures emerges a set of dynamics, organized around the project deadline, which give the global workplace its dynamism but also generate certain costs and dilemmas for the participants in the global workplace. Conflicts over these dilemmas of time-space intensification constitute the new politics of the globalization of knowledge work.

What then will be the central controversies on this new contested terrain? The two phases of time-space intensification create characteristics advantages and dilemmas for knowledge 
workers such as the software developers in this chapter, for firms such as USTech and Womble Software and for the (largely invisible) social actors beyond the industry with an interest in its social organization. While these dynamics and dilemmas have been recognized for some time in the global informational industries globalization intensifies them ${ }^{20}$.

Certain characteristic organizational problems are likely to emerge - these are the internal organizational dilemmas of time-space intensification. In the pre-release phase the introversion of the team, the intensification of time and the pressures imposed by the deadline create the conditions which lead to employee burnout - manifested in the exhaustion of the team members up to and after the deadline and also in the decision made by Ramesh (some 5 months after I left the team) to resign due to over-work. This creates problems for the organization as the team's introversion cuts it off from the rest of the organization and raises the danger of organizational involution and the distancing of teams from one another, even teams working on related technical or business issues. For the Womble team this can be seen in the antagonistic attitude to the graphics team in California, a set of relationships which, if more cooperative, could have been very valuable in improving the product under development.

In the post-deadline phase the team solidarity fragments and the team members begin to look beyond the team for future opportunities. The extroverted phase is when employees can turn to the labour market to gain the rewards of their new-found expertise and the organization can assemble a new group of employees with new sets of skills and resources into a project team for the next phase of the development effort. However, there is also a significant cost associated with the high levels of employee turnover within the industry. The accumulated knowledge of the Womble software product which has built up within the team is now dissipated throughout the industry. This constitutes a significant loss of firm-specific knowledge from Womble's point of view and also a loss of the effort put into developing effective working relationships within the team. There are therefore clear organizational costs attached to failure to address these internal dilemmas ${ }^{21}$.

Time-space intensification also causes certain external social dilemmas. The pressure and introverted character of the pre-deadline phase, and the resulting insulation of such workers and the organization of work from any kind of broader social accountability, make it all the more difficult to reconcile the team structure and culture with broader social concerns. This is manifested in at least two areas. The most directly obvious is the work-family nexus where work demands come to dominate family life, leaving very little space for workers to negotiate alternative work and family time arrangements. Secondly, as technology increasingly penetrates 
our everyday social practices the involvement of users in decisions regarding these technologies becomes more and more crucial. However, the isolation and insulation of the developers during their most creative and innovative phase militates strongly against any meaningful interaction with social actors from outside the team. To the extent that we might fear the arrival of the Weberian 'iron cage' in the form of a society dominated by large, centralized organizations there is some promise in the decentralized organizational forms compatible with this high mobility system. However, although organizations no longer have the same rigid bureaucratic structures insulating them from social accountability the intensification of time ultimately results in a similar outcome.

The post-deadline phase of high mobility creates a very high degree of volatility and insecurity in the labour market so that employees lack strong employment guarantees. This is not currently a major issue in the Irish industry given the generally very high demand for software skills. Even in the current tight labour market, 'employment security' gives way to 'employability security" ${ }^{22}$. However, when career gains are based on the threat of mobility this seems to inevitably lead to increased labour market inequality as the threat to leave is only effective when replacing the employee is difficult. As it is inherently based on scarcity, the limits of mobility as a universal career strategy are clear. This seems likely to be a contributing factor to the spiraling wage inequality in Ireland over the past 10 years $^{23}$.

These internal and external dilemmas of time-space intensification are all the more crucial given that the economic success of the Republic of Ireland over the past 10 years has been built upon the success of industries such as software ${ }^{24}$. The politics of the conference call became the new politics of the global workplace - distant yet closely integrated into operations in the core, less hierarchical but nonetheless subject to new forms of power relations. As these global workplaces spread through economies such as Ireland's, the dilemmas of time-space intensification will become central economic and social issues for societies incorporated into new, deeper processes of globalization. The value of global ethnography is its ability to reveal these dilemmas as aspects of a 'contested terrain' of globalization, rather than as inevitable outcomes of an apolitical process.

\section{References}

Baron , J., M. D. Burton and M. Hannan. "The road taken: origins and early evolution of employment systems in emerging companies.” Industrial and Corporate Change 5

(1996): 239-275. 
Barrett, A., T. Callan and B. Nolan. "Rising Wage Inequality, Returns to Education and Labour Market Institutions: Evidence from Ireland” British Journal of Industrial Relations 37 (1999): 77-100.

Berman, M. All That Is Solid Melts Into Air: The Experience of Modernity London: Penguin, 1982

Bluestone,B. and B.Harrison. The Deindustrialization of America New York: Basic Books, 1982.

Brown, S. and K. Eisenhardt. 'The Art of Continuous Change’ Administrative Science Quarterly 42, (1997): 1-34.

Burawoy,M. The Politics of Production London: Verso, 1985.

Castells,M. The Rise of the Network Society: Volume 1 Cambridge Mass.: Blackwell, 1996.

Castells, M. and P.Hall.Technopoles of the World New York.: Routledge, 1994.

Fynes, B., T.Morrissey, W.K.Roche, B.J.Whelan, J.Williams. Flexible Working Lives: The Changing Nature of Working Time Arrangements in Ireland Dublin: Oak Tree Press, 1996.

Giddens, A. The Consequences of Modernity Oxford: Blackwell, 1991.

Harvey, D. The Condition of Postmodernity Oxford: Blackwell, 1989.

Kanter, R.M. World Class New York. : Simon and Schuster, 1995.

Kidder, T. The Soul of a New Machine New York:Avon Books, 1981.

Kunda,G. Engineering Culture Philadelphia: Temple University Press, 1993.

Lave, J. and E. Wenger. Situated Learning: Legitimate Peripheral Participation Cambridge: Cambridge University Press, 1993.

Office of Technology Policy. America's New Deficit: The Shortage of Information Technology Workers Washington: US Department of Commerce, Technology Administration, 1997. (www.ta.doc.gov/reports/itsw/itsw.pdf)

O’Malley, E., Industry and Economic Development. Dublin: Gill and Macmillan, 1989.

Ó Riain, S. 'An Offshore Silicon Valley?’Competition and Change 2 (1997): 175-212

Ó Riain, S. 'The Birth of a Celtic Tiger?'Communications of the ACM, 40 (1997): 11-16.

Ó Riain, S. Remaking the Developmental State: The Irish Software Industry in the Global Economy Unpublished dissertation, Department of Sociology, University of California, Berkeley, 1999.

Perlow, L.Finding Time Cornell: ILR Press, 1997.

Perlow, L. 'Boundary Control: The social ordering of work and family time in a high-tech corporation’ Administrative Science Quarterly 43 (1998): 328-357.

Piore,M. and C. Sabel. The Second Industrial Divide New York: Basic Books, 1984.

Reich, R. The Work of Nations New York.: Vintage Books, 1991.

Sassen, S. The Global City Princeton: Princeton University Press, $1990 .$.

Saxenian, A. Regional Advantage Cambridge: Harvard University Press, 1994.

Shaiken,H. Mexico in the Global Economy San Diego: Center for US-Mexican Studies, 1990.

Storper,M. The Regional World: Territorial Development in a Global Economy London: Guilford Press, 1997.

Tierney, M. 'Negotiating a Software Career: Informal Work Practices and 'The Lads' in a Software Installation” In K.Grint and R.Gill (Eds.) The Gender-Technology Relation: Contemporary Theory and Research, London: Taylor and Francis, 1995.

Wellman, B. et al. 'Computer Networks as Social Networks' Annual Review of Sociology 22 (1996): 213-238. 
${ }^{1}$ Robert Reich, The Work of Nations

${ }^{2}$ Anthony Giddens, The Consequences of Modernity. Giddens argues that globalization occurs in a process of timespace distanciation as space and time are 'distanciated' from (lifted out of) their local contexts. There are two main mechanisms through which this happens: the use of symbolic tokens (universal media of exchange/ interaction such as money) and of expert systems (shared bodies of technical knowledge that can be applied in a wide variety of contexts)

${ }^{3}$ Marshall Berman, All That Is Solid Melts Into Air; David Harvey, The Condition of Postmodernity; Manuel Castells, The Rise of the Network Society. Harvey argues that globalization is characterized by a process of timespace compression where the speed up of time in the global economy also serves to compress the autonomy of local space and social context as different places are integrated into an increasingly universal capitalist economy.

${ }^{4}$ Barry Bluestone and Bennett Harrison, The Deindustrialization of America; Michael Burawoy, The Politics of Production; Harley Shaiken, Mexico in the Global Economy.

${ }^{5}$ We might refer to this perspective as time-space embedding as embeddedness of workplaces in their local social contexts appears to provide a solution to the speed up of the global economy, giving the successful workplaces some insulation from these pressures and perhaps even re-embedding time itself in local contexts. See Michael Piore and Charles Sabel, The Second Industrial Divide; AnnaLee Saxenian, Regional Advantage; Michael Storper, The Regional World.

${ }^{6}$ See Leslie Perlow, Finding Time, 'Boundary Control' for detailed empirical analyses of these issues in a software workplace.

${ }^{7}$ Eoin O’Malley, Industry and Economic Development.

${ }^{8}$ For a more detailed analysis of this process see Seán Ó Riain “The Birth of a Celtic Tiger?', 'An Offshore Silicon Valley?', Remaking the Developmental State.

${ }^{9}$ IBM's employment guarantee collapsed with a reduction of 140,000 in a workforce of 400,000 between 1986 and 1993. For an analysis of 'corporate culture’ in such workplaces see Gideon Kunda, Engineering Culture.

${ }^{10}$ Saxenian, op cit; Baron, Burton and Hannon, 'The Road Taken'.

${ }^{11}$ Office of Technology Policy, America's New Deficit

${ }^{12}$ Seán Ó Riain, Remaking the Developmental State. See Saskia Sassen, The Global City and Saxenian, op cit. for discussion of labour markets in agglomerated industries in core regions.

${ }^{13}$ Reich, op cit.

${ }^{14}$ Much of this learning, especially in a team context, derives from what Jean Lave and Etienne Wenger call ‘situated learning'. See Lave and Wenger, Situated Learning.

${ }^{15}$ Barry Wellman et al., ‘Computer Networks as Social Networks’ p.231.

${ }^{16}$ For a discussion of this concept and a review of a variety of examples, see Manuel Castells and Peter Hall, Technopoles of the World. 
${ }^{17}$ See for example Rosabeth Moss Kanter, World Class; Manuel Castells, The Rise of the Network Society.

${ }^{18}$ For a more detailed analysis of these processes, based on a case study of a software company in Ireland in the mid-1980s, see Tierney, 'Negotiating a Software Career'.

${ }^{19}$ Fynes, B., T.Morrissey, W.K.Roche, B.J.Whelan, J.Williams, Flexible Working Lives.

${ }^{20}$ For a classic account of these dynamics in a computer design workplace in the 1970s see Tracy Kidder, The Soul of a New Machine.

${ }^{21}$ For an organizational and management theory perspective, see Brown and Eisenhardt, 'The Art of Continuous Change'.

${ }^{22}$ See Kanter, op cit. for a discussion of this concept as developed in a study of a software company in Massachusetts.

${ }^{23}$ For a detailed analysis of trends from 1987 to 1994 see Alan Barrett, Tim Callan and Brian Nolan, 'Rising Wage Inequality, Returns to Education and Labour Market Institutions’.

${ }^{24}$ For a more detailed analysis of the growth of the Irish software industry, with particular reference to the potential and limits of state-society alliances in shaping the industry's development and impact, see Ó Riain, Remaking the Developmental State. 